\title{
Analgesic and Anti-Inflammatory Activities of the Methanol Extract from Pogostemon cablin
}

\author{
Tsung-Chun Lu, ${ }^{1}$ Jung-Chun Liao, ${ }^{2}$ Tai-Hung Huang, ${ }^{2}$ Ying-Chih Lin, ${ }^{3}$ Chia-Yu Liu, ${ }^{4}$ \\ Yung-jia Chiu, ${ }^{1}$ and Wen-Huang Peng ${ }^{1}$ \\ ${ }^{1}$ Graduate Institute of Chinese Pharmaceutical Sciences, College of Pharmacy, China Medical University, 91, \\ Hsieh Shih Road, Taichung, Taiwan \\ ${ }^{2}$ School of Pharmacy, College of Pharmacy, China Medical University, 91, Hsieh Shih Road, Taichung, Taiwan \\ ${ }^{3}$ Department of Optometry, Jen-Teh Junior College of Medicine, Nursing and Management, No. 79-9, \\ Sha-Luen-Hu, Xi Zhou Li, Hou-Loung Town, Miaoli County 35664, Taiwan \\ ${ }^{4}$ Department of Nursing, Jen-Teh Junior College of Medicine, Nursing and Management, No. 79-9, \\ Sha-Luen-Hu, Xi Zhou Li, Hou-Loung Town, Miaoli County 35664, Taiwan
}

Correspondence should be addressed to Wen-Huang Peng, whpeng@mail.cmu.edu.tw

Received 1 June 2009; Accepted 14 October 2009

Copyright (๑) 2011 Tsung-Chun Lu et al. This is an open access article distributed under the Creative Commons Attribution License, which permits unrestricted use, distribution, and reproduction in any medium, provided the original work is properly cited.

\begin{abstract}
Pogostemon cablin (PC) is a herbal medicine traditionally applied to treat not only common cold, nausea and diarrhea but also headache and fever. The aim of this study was to investigate the analgesic and anti-inflammatory properties of standardized PC methanol extract $(\mathrm{PCMeOH})$ in vivo. Investigations were performed in mice with two analgesic models. One was acetic acidinduced writhing response and the other formalin-induced paw licking. The anti-inflammatory effect was tested by $\lambda$-carrageenan (Carr)-induced mice paw edema. These analgesic experimental results indicated that $\mathrm{PCMeOH}(1.0 \mathrm{~g} / \mathrm{kg}) \mathrm{decreased}$ the acetic acid-induced writhing responses and $\mathrm{PCMeOH}(0.5$ and $1.0 \mathrm{~g} / \mathrm{kg})$ decreased the licking time in the second phase of the formalin test. Moreover, Carr-induced paw edema inflammation was significantly reduced in a dose-dependent manner when $\mathrm{PCMeOH}$ $(0.5$ and $1.0 \mathrm{~g} / \mathrm{kg})$ was administered 3 and $4 \mathrm{~h}$ after the Carr injection. Mechanistic studies showed that PCMeOH decreased the levels of malondialdehyde in the edema paw by increasing the activities of anti-oxidant enzymes, such as superoxide dismutase, glutathione peroxidase and glutathione reductase, in the liver and decreasing the cyclooxygenase 2 and tumor necrosis factor- $\alpha$ activities in the edema paw. This study has demonstrated the analgesic and anti-inflammatory effects of PCMeOH, thus verifying its popular use in traditional medicine.
\end{abstract}

\section{Introduction}

Cerebral and coronary artery diseases are the leading causes of death around the world. More and more researchers have demonstrated that abnormal inflammatory cells form a plaque and play an essential role in the pathogenesis and progression of atherosclerosis [1]. Anti-inflammatory agents have been shown to have good effects on the prevention and treatment of atherosclerosis and coronary artery diseases [2]. Therefore, developing novel anti-inflammatory drugs is very important today.

Analgesic drugs operate in different ways on the peripheral and central nervous systems. Narcotic drugs, such as morphine, have analgesic activity, which inhibits the delivery of pain impulses $[3,4]$. Peripheral drugs include paracetamol and non-steroidal anti-inflammatory drugs (NSAIDs). Only NSAIDs possess analgesic and anti-inflammation activity due to the mechanism of inhibiting cyclooxygenases (COXs) for the decrease in prostaglandin (PG) production, which consequently reduces pain and inflammation. However, the NSAIDs used clinically are often of limited application because of their common side effects, such as gastrointestinal (GI) hemorrhage [5]. As to COX, COX-1 is thought to provide cytoprotection, whereas COX-2 inhibitor may have selective anti-inflammatory properties and lack GI side effects [6].

PC is native to tropical regions of Asia and now cultivated extensively in Caribbean countries, China, India, Indonesia, Malaysia, Mauritius, Philippines, West Africa and Vietnam. Its dried aerial part is commonly known 
as "Guang-Huo-Xiang" [7]. Several studies have been performed on the composition of PC and presence of patchouli alcohol, pogostone, eugenol, $\alpha$-bulnesene, rosmarinic acid and others [8]. Essential oils constitute $\sim 1.5 \%$ of PC, among which $>50 \%$ is patchouli alcohol. The alcoholic extract of PC contains the major active ingredient [9]. PC is used by traditional physicians in treating not only the common cold, nausea and diarrhea but also headaches and fever [10]. The volatile oil of PC has been widely used in cosmetics and oral hygiene products, such as scent perfumes and flavor toothpaste. Pharmacological activities of this oil have been demonstrated repeatedly in modern research, including its anti-emetic, anti-bacterial and anti-fungal activities [11-13]. PC contains sesquiterpenes cytotoxic chalcones [14] and anti-mutagenic flavones. However, there is little research regarding the information on the analgesic and antiinammatory activities of $\mathrm{PC}$ in vivo and in vitro.

This study investigated the anti-inflammatory and analgesic activities of PC methanol extract $(\mathrm{PCMeOH})$. Its analgesic activity was evaluated using the acetic acid-induced writhing response and formalin test, because acetic acidinduced abdominal constriction was associated with the involvement of peripheral mechanisms [15]. The formalin test was performed according to the method of Dubuisson and Dennis [16]. The time spent in behavioral responses to nociception, including biting, licking and scratching of the injected paw, was noted. The test conducted involves a biphasic response with the early phase, the direct effect of formalin on nociceptors and the late phase due to inflammation [17].

The anti-inflammatory activity of $\mathrm{PCMeOH}$ was determined using the Carr-induced paw edema model, which is a useful model to assess inflammation. The model has been correlated with the increased production of PGs and, more recently, has been attributed to the induction of inducible COX-2 in the hind paw [18]. The Carr-induced inflammatory response has been linked to neutrophil infiltration and the production of neutrophil-derived free radicals, such as hydrogen peroxide $\left(\mathrm{H}_{2} \mathrm{O}_{2}\right)$, superoxide $\left(\mathrm{O}_{3}^{-}\right)$and hydroxyl radicals $\left(\mathrm{OH}^{-}\right)$, as well as to the release of other neutrophilderived mediators [19]. Superoxide dismutase (SOD), the first line of defense in the body against $\mathrm{O}_{2}$, is considered the most effective anti-oxidant [20]. Glutathione peroxidase (GPx), which accelerates the reduction of $\mathrm{H}_{2} \mathrm{O}_{2}$ or other organic hydroperoxides ( $\mathrm{ROOH}$ ) in the presence of GSH, serves as a second line of defense against hydroperoxides [21]. Glutathione reductase $(\mathrm{GRx})$ plays a crucial role in cellular defense against oxidative stress by preventing accumulation of GSSG, thus maintaining the redox state [22]. This study also observed tumor necrosis factor- $\alpha$ (TNF$\alpha$ ) level and COX-2 protein expression in the edema paw and activities of anti-oxidant enzymes in the liver. Indomethacin (Indo) was used as a positive control.

\section{Materials and Methods}

2.1. Plant Material. The plants of Pogostemon cablin (Blanco) Benth (Family Lamiaceae) were collected from Taichung, Taiwan, in July 2006 and identified by Dr Chao-Lin Kuo, leader of the School of Chinese Medicine Resources (SCMR). The voucher specimen (Number: CMU MO 0720) was deposited at SCMR.

2.2. Preparation of Plant Extract. Dried PC (1800 g), made from the aerial part and leaves of plants, was sliced into small pieces and ground into a powder. Ten liters of methanol was added to the dried powder and extracted for $24 \mathrm{~h}$ per cycle four times. The extracts were filtered, combined and concentrated under reduced pressure at $40^{\circ} \mathrm{C}$ to obtain the $\mathrm{PCMeOH}$ extract. The yield ratio of the $\mathrm{PCMeOH}$ extract $(53.1 \mathrm{~g})$ was $2.95 \%$.

2.3. Animals. Each experimental group consisted of eight Imprinting Control Region (ICR) mice (18-22 g). They were obtained from the National Laboratory Animal Breeding and Research Center, National Science Council, Taiwan, and housed in standard cages at a constant temperature of $22 \pm$ $1{ }^{\circ} \mathrm{C}$ and relative humidity of $55 \pm 5 \%$ with 12 -h dark-light cycles $(08: 00-20: 00)$ for at least 1 week before the experiment. They were fed with food and water ad libitum. The experimental protocol was approved by the Committee on Animal Research, China Medical University. The minimum number of animals and duration of observations required to obtain consistent data were used.

2.4. Chemicals. $\lambda$-Carrageenan, indomethacin, glycine, phosphate-buffered saline (PBS) solution and glutaraldehyde were purchased from Sigma-Aldrich, Inc. (St Louis, MO, USA). Formalin was purchased from Nihon Shiyaku Industry Ltd, Japan; the activity assay kits, from Randox Laboratory Ltd; TNF- $\alpha$, from Biosource International, Inc., and COX-2 anti-body (ab16701), from Abcam plc.

2.5. Acetic Acid-Induced Writhing Response. The writhing test in mice was carried out using the method proposed by $\mathrm{Lu}$ [23]. The writhes were induced by intraperitoneal (i.p.) injection of $1.0 \%$ acetic acid $(\mathrm{v} / \mathrm{v}, 0.1 \mathrm{~mL} / 10 \mathrm{~g}$ body weight). Three different doses $(0.1,0.5$ and $1.0 \mathrm{~g} / \mathrm{kg}$ ) of $\mathrm{PCMeOH}$ were administered orally to each group of mice $60 \mathrm{~min}$ before acetic acid injection. Indo as a positive control was administered $30 \mathrm{~min}$ prior to chemical stimulus. The data were recorded $5 \mathrm{~min}$ after acetic acid injection. The number of muscular contractions was counted over a period of $10 \mathrm{~min}$ after acetic acid injection. The data collected would represent the total number of writhes observed during the 10-min period.

2.6. Formalin Test. The method used in our study was similar to that described in the previous study [24]. Pain was induced by injecting $20 \mu \mathrm{L}$ of $5 \%$ formalin in distilled water in the subplantar of the right hind paw. $\mathrm{PCMeOH}$ $(0.1,0.5$ and $1.0 \mathrm{~g} / \mathrm{kg}$, p.o.) was administered $60 \mathrm{~min}$ before formalin injection. Indo $(10 \mathrm{mg} / \mathrm{kg}$, p.o.) was administered $30 \mathrm{~min}$ before formalin injection. The control group received the same volume of saline by oral administration. These mice were individually placed in a transparent Plexiglas cage $(25 \times 15 \times 15 \mathrm{~cm})$. The time spent for licking and biting 
the injected paw, as the indicators of pain, was recorded separately at $0-5 \mathrm{~min}$ (first phase or neurogenic pain) and 20-30 min (second phase or inflammatory pain) [17].

2.7. Carr-Induced Mice Paw Edema. The anti-inflammatory activity of $\mathrm{PCMeOH}$ was determined by the Carr-induced edema test in the hind paws of mice. Male ICR mice (eight per group) were fasted for $24 \mathrm{~h}$ before the experiment, with free access to water. Fifty microliters of 1\% Carr suspension in saline was injected into the plantar side of the right hind paws of the mice [25]. Paw volume was measured immediately at $1,2,3$ and $4 \mathrm{~h}$ after the administration of the Carr using a plethysmometer. The degree of swelling was evaluated by the delta volume $(a-b)$, where $a$ and $b$ are the volume of the right hind paw after and before the Carr treatment, respectively. Indo was used as a positive control compound [26], which was administered intraperitoneally (i.p.) $150 \mathrm{~min}$ after Carr injection. $\mathrm{PCMeOH}$ was administered orally $120 \mathrm{~min}$ after Carr injection.

In the secondary experiment, the whole right hind paw and liver tissues were taken at the third hour. The right hind paw tissue was rinsed in ice-cold normal saline and immediately placed in cold normal saline four times their volume and finally homogenized at $4^{\circ} \mathrm{C}$. Then, the homogenate was centrifuged at $11,270 \mathrm{~g}$ for $5 \mathrm{~min}$. The supernatant was obtained and stored at $-80^{\circ} \mathrm{C}$ for the TNF$\alpha, \mathrm{COX}-2$ and malondialdehyde (MDA) assays.

On the other hand, the whole liver tissue was rinsed in ice-cold normal saline and immediately placed in cold normal saline of the same volume and finally homogenized at $4^{\circ} \mathrm{C}$. Then, the homogenate was centrifuged at $11,270 \mathrm{~g}$ for $5 \mathrm{~min}$. The supernatant was obtained and stored at $-80^{\circ} \mathrm{C}$ for the anti-oxidant enzyme (SOD, GPx and GRx) activity assays.

2.7.1. MDA Assay. MDA was evaluated by the thiobarbituric acid-reacting substance (TRARS) method [27]. First, the paw tissues were homogenized in buffered saline (1:4); then, $400 \mu \mathrm{L}$ of 1,1,3,3-tetraethoxypropan trichloroacetic acid $(28 \% \mathrm{w} / \mathrm{v})$ was added to $200 \mu \mathrm{L}$ of this mixture and centrifuged in $3000 \mathrm{~g}$ for $30 \mathrm{~min}$. After that, $300 \mu \mathrm{L}$ of the supernatant was added to $150 \mu \mathrm{L}$ of 2 -thiobarbituric acid $(1 \% \mathrm{w} / \mathrm{v})$. The mixture was incubated for $45 \mathrm{~min}$ in a boiling water bath, and then $450 \mu \mathrm{L}$ n-butanol was added; the solution was centrifuged and cooled, and absorption of the supernatant was recorded in $532 \mathrm{~nm}$ by the microplate reader (VersaMax, Massachusetts, USA). Tetramethoxypropane was used as standard. MDA levels were expressed as nanomoles per milligram of protein. Protein concentration was measured by Lowry method [28]. Bovine serum albumin was used as standard.

2.7.2. Anti-Oxidant Enzymes' Activities. The following biochemical parameters were analyzed to detect the antioxidant activities of PC by the methods described below. SOD enzyme activity was determined at room temperature according to the method of Misra and Fridovich [29]. One hundred microliters of tissue extract was added to

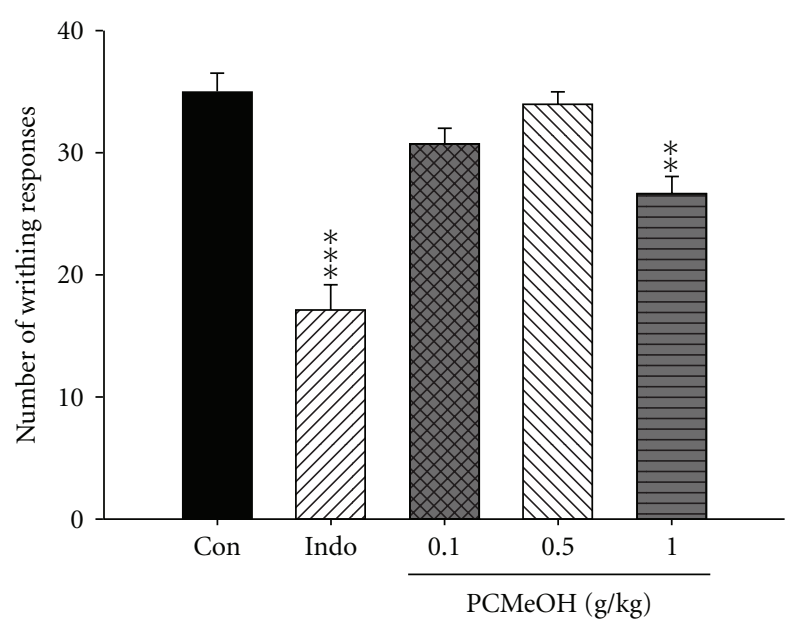

FIGURE 1: Analgesic effect of the PCMeOH and Indo on acetic acidinduced writhing response in mice. Each value represents mean \pm SEM. ${ }^{* *} P<.01,{ }^{* * *} P<.001$ as compared with the control (Con) group. (One-way ANOVA followed by Scheffe's multiple range test).

$880 \mu \mathrm{L}$ (pH 10.2, 0.1 mM EDTA) of carbonate buffer. Twenty microliters of $30 \mathrm{mM}$ epinephrine (in $0.05 \%$ acetic acid) was added to the mixture at $480 \mathrm{~nm}$ for $4 \mathrm{~min}$ on a Hitachi U 2000 Spectrophotometer. The enzyme activity was expressed as the amount of enzyme that inhibits the oxidation of epinephrine by $50 \%$, which is equal to 1 unit.

GPx enzyme activity was determined according to the method of Flohe and Gunzler [30] at $37^{\circ} \mathrm{C}$. The reaction mixture composed of $500 \mu \mathrm{L}$ phosphate buffer, $100 \mu \mathrm{L} 0.01$ M GSH (reduced form), $100 \mu \mathrm{L} 1.5 \mathrm{mM} \mathrm{NADPH}$ and $100 \mu \mathrm{L}$ GRx (0.24 units). One hundred microliters of the tissue extract was added to the reaction mixture and incubated at $37^{\circ} \mathrm{C}$ for $10 \mathrm{~min}$. Then, $50 \mu \mathrm{L}$ of $12 \mathrm{mM} t$-butyl hydroperoxide was added to $450 \mu \mathrm{L}$ of tissue reaction mixture and measured at $340 \mathrm{~nm}$ for $180 \mathrm{~s}$. The molar extinction coefficient of $6.22 \times 10^{-3}$ was used to determine the enzyme activity. One unit of activity is equal to the millimolar of NADPH oxidized per minute per milligram of protein.

GRx enzyme activity was determined following the method of Carlberg and Mannervik [31] at $37^{\circ} \mathrm{C}$. Fifty microliters of NADPH $(2 \mathrm{mM})$ in $10 \mathrm{mM}$ Tris buffer $(\mathrm{pH}$ 7.0) was added in the cuvette containing $50 \mu \mathrm{L}$ of GSSG $(20 \mathrm{mM})$ in phosphate buffer. One hundred microliters of tissue extract was added to the NADPH-GSSG-buffered solution and measured at $340 \mathrm{~nm}$ for $3 \mathrm{~min}$. The molar extinction coefficient of $6.22 \times 10^{-3}$ was used to determine GRx enzyme activity. One unit of activity is equal to the millimolar of NADPH oxidized per minute per milligram of protein.

2.7.3. Tissue COX-2 by Quartz Crystal Microbalance. The P-sensor 2000 designed by ANT is based on the principle of piezoelectric biosensor. It is made of three portions including electronic oscillation circuit, frequency counter and piezoelectric quartz of fixed biosensor molecule ( $p$ chip). The piezoelectric quartz crystal consists of a quartz 


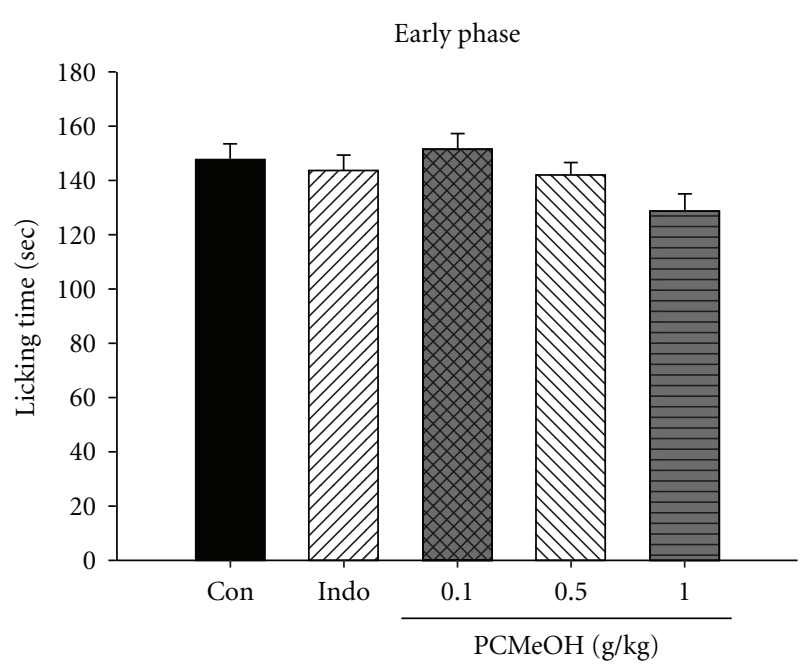

(a)

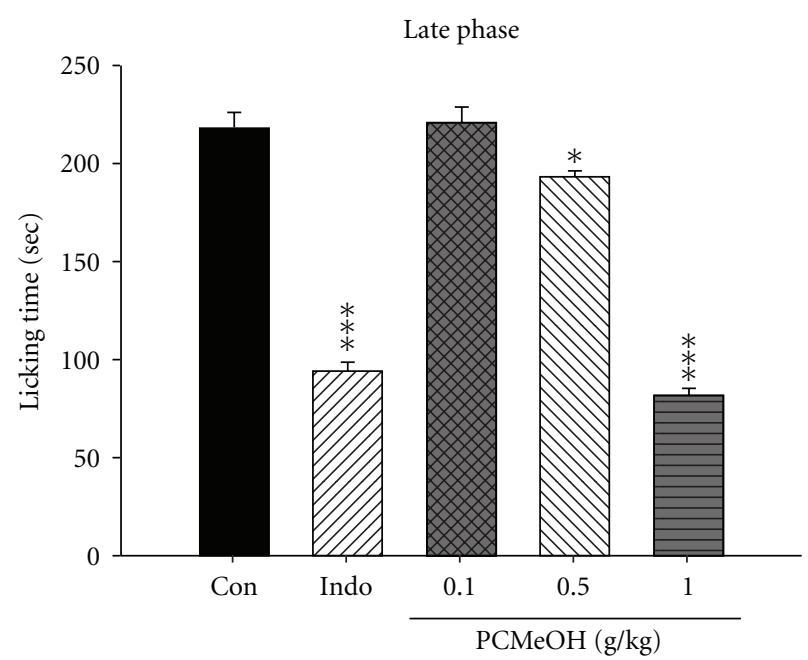

(b)

Figure 2: Analgesic effect of the PCMeOH and Indo on the (a) early phase and (b) late phase in formalin test in mice. Each value represents mean \pm SEM. ${ }^{*} P<.05,{ }^{* * *} P<.001$ as compared with the control (Con) group. (One-way ANOVA followed by Scheffe's multiple range test).

crystal slab with a layer of gold electrode on each side. It is the signal conversion component of the piezoelectric sensor chip and can convert the result sensed by the sensor molecule into electronic signal to be amplified. The function of gold electrodes is mainly to introduce an oscillating electric field perpendicular to the surface of the chip so that the internal part of the chip generates mechanical oscillation because of the piezoelectric effect. If the thickness of the quartz crystal is fixed, the mechanical oscillation will be generated at a fixed frequency. Using a suitable electronic oscillation circuit, the resonant frequency can be measured.

P-sensor 2000 (Asia New Technology, Taiwan), based on quartz crystal microbalance (QCM), was used to monitor the antibody-antigen interaction in real time [32]. The PBS, a mobile carrier, would flow through the sensor cell with

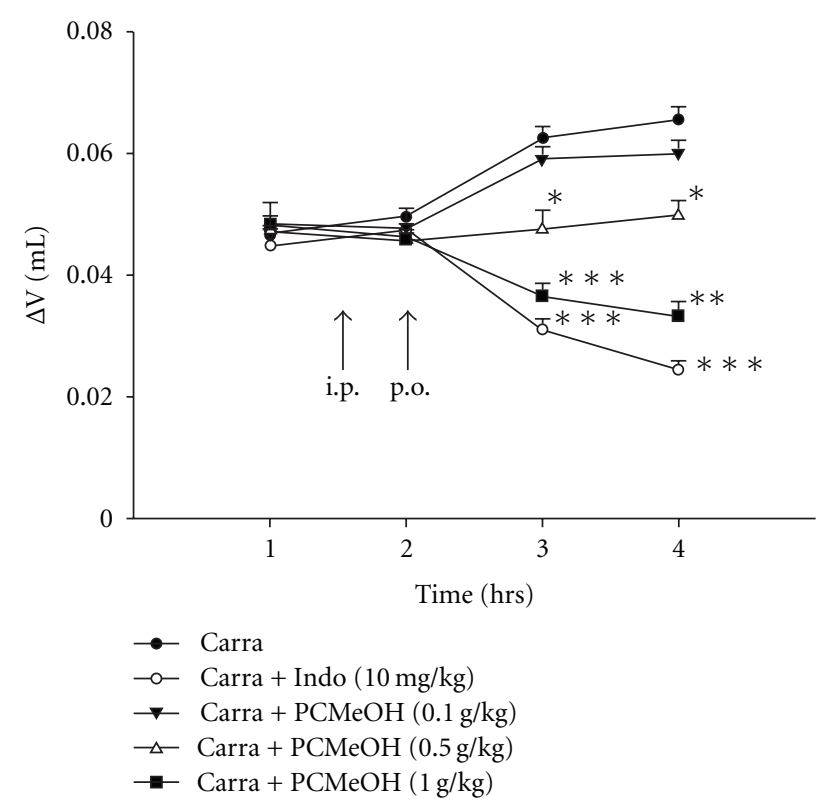

FIgure 3: Effect of the PCMeOH and Indo on hind paw edema induced by Carr in mice. Indo was administered i.p. at $150 \mathrm{~min}$ after Carr injection. PCMeOH was administered orally (p.o.) at $120 \mathrm{~min}$ after Carr injection. Each value represents mean \pm SEM. ${ }^{*} P<.05$, ${ }^{* *} P<.01,{ }^{* * *} P<.001$ as compared with the Carr group. (One-way ANOVA followed by Scheffe's multiple range test).

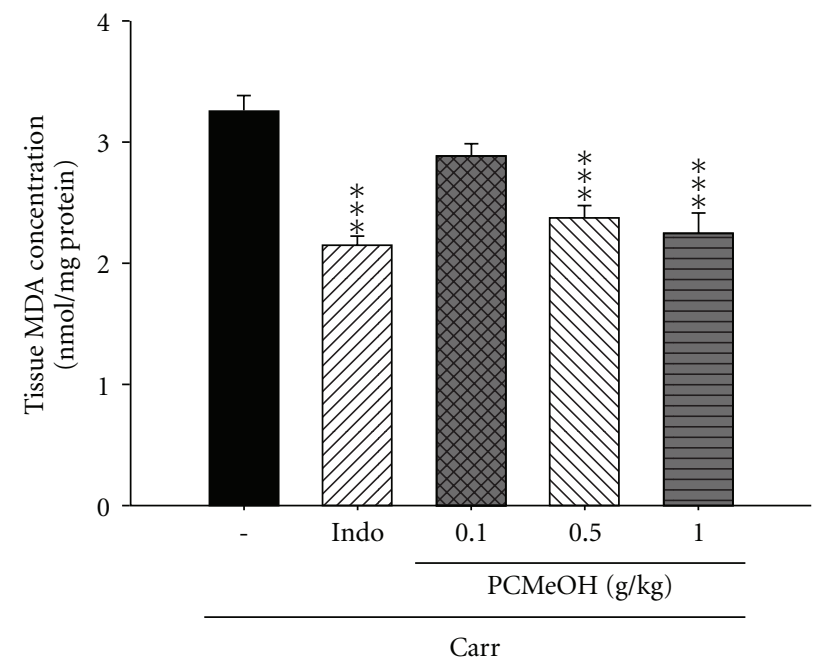

FIgure 4: The MDA accumulation of the PCMeOH and Indo at the third hour after Carr injection in the mice edema paw. Each value represents mean \pm SEM. ${ }^{* * *} P<.001$ as compared with the Carr group. (One-way ANOVA followed by Scheffe's multiple range test).

the antibody-immobilized chip in flow rate of $30 \mu \mathrm{L} / \mathrm{min}$ and clean the fluid lines of QCM, alternating with the $1 \mathrm{~N}$ $\mathrm{NaOH}$ and $1 \mathrm{~N} \mathrm{HCl}$ solution and ultra-pure water before the measurement. After the introduction of PBS to fill the sensor cell, the frequency shift of QCM reached a steady equilibrium (" $\Delta \mathrm{F}$ " $<0.2 \mathrm{~Hz} / \mathrm{min}$ ) and was defined as a zero baseline "F0". Upon the injection of experimental solution into the sensor cell, the dynamic interactions between antigens and 


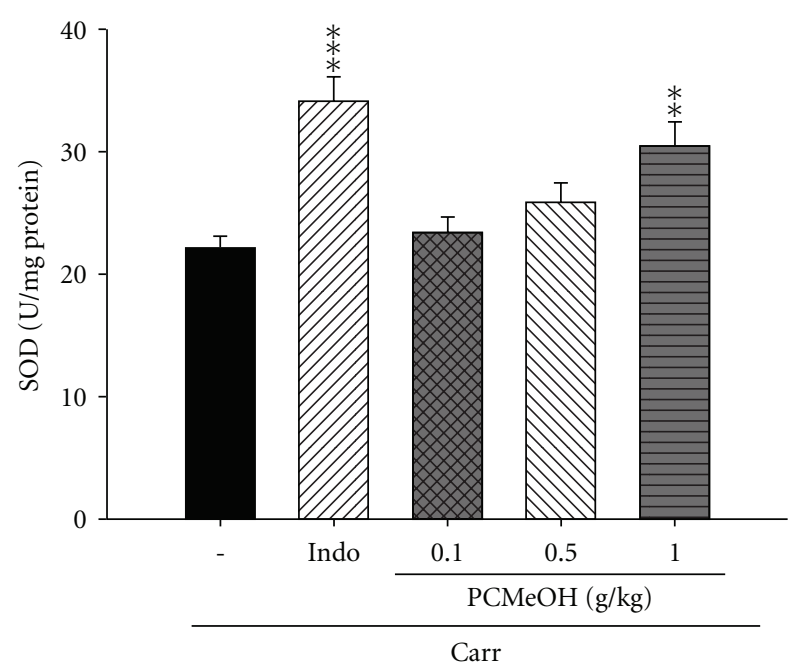

(a)

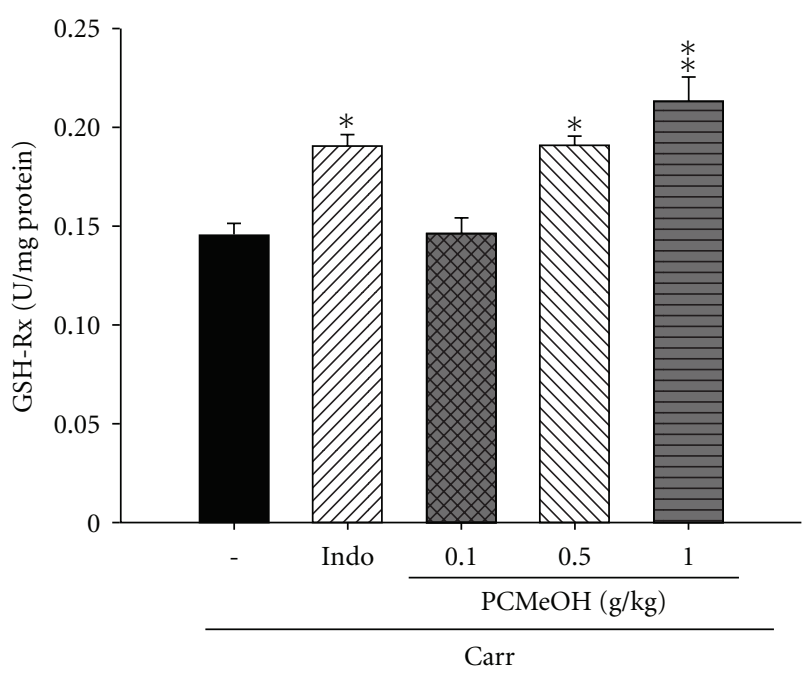

(b)

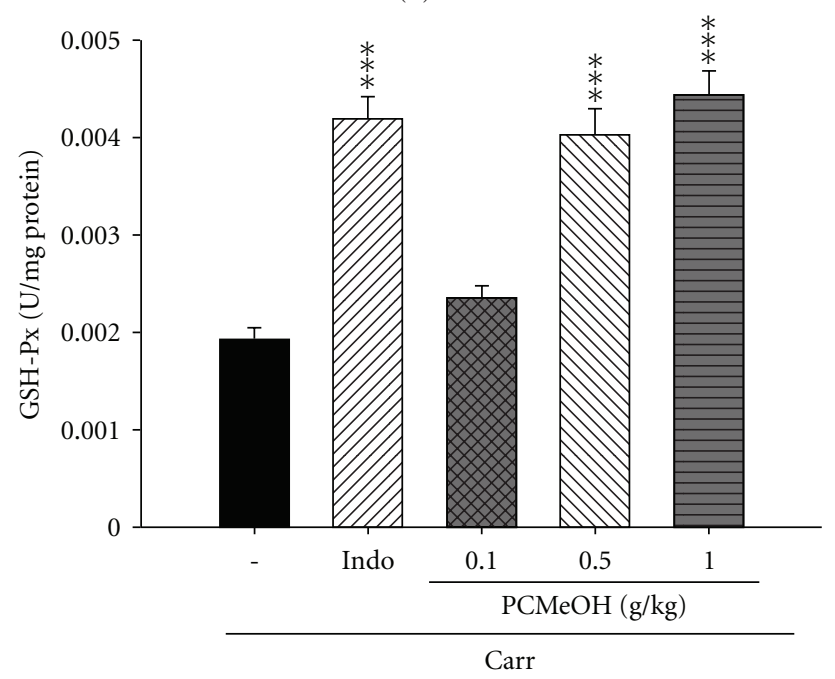

(c)

FIGURE 5: Effect of the PCMeOH and Indo on the liver (a) SOD, (b) GRx and (c) GPx activities in mice. Each value represents mean \pm SEM. ${ }^{*} P<.05,{ }^{* *} P<.01,{ }^{* * *} P<.001$ as compared with the Carr group. (One-way ANOVA followed by Scheffe's multiple range test).

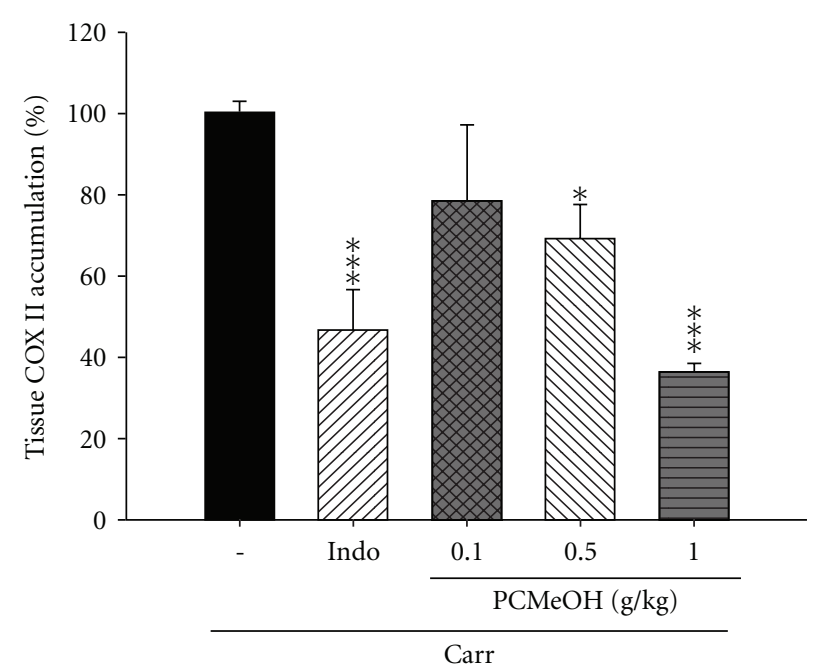

FIgure 6: The COX-2 accumulation of the PCMeOH and Indo at the third hour after Carr injection in the mice edema paw. All values represent means \pm SEM $(n=10) .{ }^{*} P<.05,{ }^{* * *} P<.001$ as compared with the Carr group. (One-way ANOVA followed by Scheffe's multiple range test).

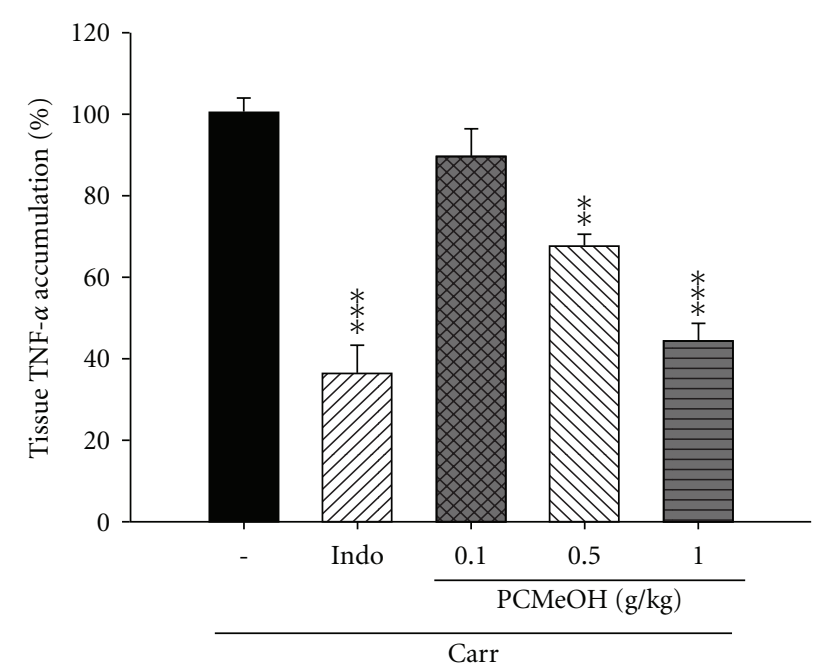

Figure 7: The TNF- $\alpha$ accumulation of the PCMeOH and Indo at third hour after Carr injection in the mice edema paw. All values represent as means $\pm \operatorname{SEM}(n=10) .{ }^{* *} P<.01,{ }^{* * *} P<.001$ as compared with the Carr group. (One-way ANOVA followed by Scheffe's multiple range test).

immobilized antibodies were monitored, and the frequency shifts were recorded for the next steady equilibrium, "F". Thus, the apparent frequency change of crystal oscillator, " $\Delta F$ ", can be measured by subtracting " $F$ " from "F0". All of PBS and diluted sera solutions were filtered with Millex GP filter unit $(0.22 \mu \mathrm{m}$, PES membrane; Millipore, Ireland) and degassed before use. The sensor chips were disposable to ensure the sensitivity and reproducibility of each of the QCM experiments. With a temperature controller, the temperature of the sensor cell was controlled at a constant temperature 


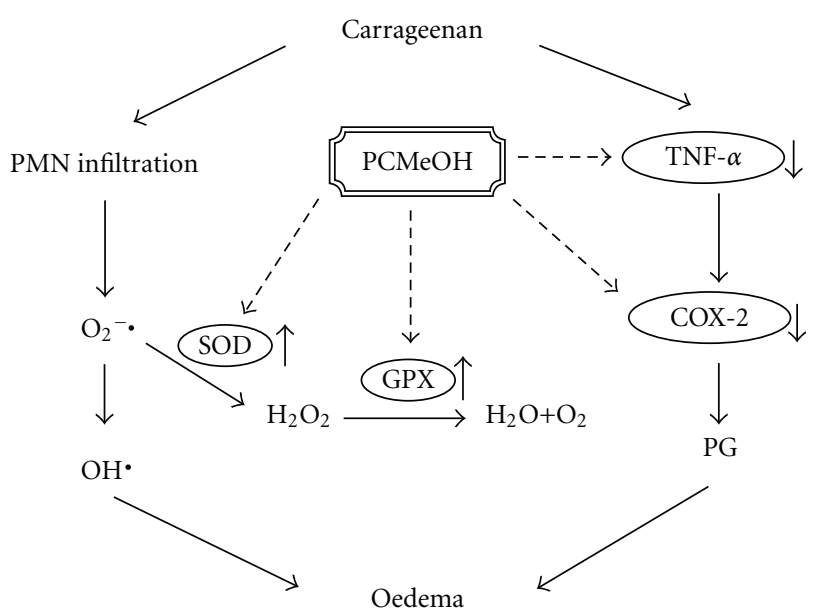

Figure 8: Proposed model of mechanisms in Carr-induced acute inflammatory response in the mice hind paw.

of $25.0( \pm 0.1)^{\circ} \mathrm{C}$ to suppress the fluctuations of kinetics by ambient environment.

2.8. Tissue TNF- $\alpha$ by ELISA. Tissue levels of TNF- $\alpha$ were determined using a commercially available enzyme-linked immunosorbent assay (ELISA) kit according to the manufacturer's instruction. The measurements were performed according to the manufacturer's protocols. The absorbance at 450 and $540 \mathrm{~nm}$ was measured on a microplate reader (VersaMax, Massachusetts, USA). TNF- $\alpha$ was determined from a standard curve for the combination of these cytokines [33].

2.8.1. Statistical Analysis. All the data were expressed as mean \pm SEM. Statistical analysis was carried out using one-way analysis of variance (ANOVA), followed by Scheffe's multiple range test. The criterion for statistical significance was $P<$ .05 .

\section{Results}

3.1. Acetic Acid-Induced Writhing Response. The results of acetic acid-induced writhing responses in mice that indicate the analgesic activity of the methanol extracts of $\mathrm{PCMeOH}$ are presented in Figure 1. It was found that the $\mathrm{PCMeOH}$ $(1.0 \mathrm{~g} / \mathrm{kg})$ and Indo $(10 \mathrm{mg} / \mathrm{kg})$ showed inhibition in this model $(P<.01-.001)$.

3.2. Formalin Test. PCMeOH demonstrated a dosedependent relationship in both phases of formalin-induced pain. In the early phase, there are no significant inhibitions with the dose of PCMeOH $(0.1,0.5$ and $1.0 \mathrm{~g} / \mathrm{kg})$ and Indo $(10 \mathrm{mg} / \mathrm{kg}$ ) compared with the control group (Figure 2(a)). In the late phase, the dose of $\mathrm{PCMeOH}(0.5$ and $1.0 \mathrm{~g} / \mathrm{kg})$ and Indo $(10 \mathrm{mg} / \mathrm{kg})$ significantly reduced the nociception
$(P<.05-.001 ;$ Figure 2(b)).

3.3. Carr-Induced Mice Paw Edema. PCMeOH (0.5 and $1.0 \mathrm{~g} / \mathrm{kg})$ was observed to inhibit $(P<.05-.001)$ the development of paw edema induced by Carr after 3 and $4 \mathrm{~h}$ of treatment. Indo $(10 \mathrm{mg} / \mathrm{kg})$ significantly decreased the Carrinduced paw edema after 3 and $4 \mathrm{~h}$ of treatment $(P<.001$; Figure 3).

3.3.1. MDA Level. In the control group, MDA level in the edema paw induced by Carr increased significantly. However, the MDA level decreased significantly with treatment of $\mathrm{PCMeOH}(0.5$ and $1.0 \mathrm{~g} / \mathrm{kg})$, as well as $10 \mathrm{mg} / \mathrm{kg}$ Indo $(P<$ .001 ; Figure 4).

3.3.2. The Activities of Anti-Oxidant Enzymes. At the third hour following the intrapaw injection of Carr, liver tissues were also analyzed for the biochemical parameters, such as SOD, GPx and GRx activities. SOD activity in the liver tissue decreased significantly by Carr administration. SOD activity increased significantly after treatment with $10 \mathrm{mg} / \mathrm{kg}$ Indo $(P$ $<.001$; Figure 5(a)). Carr administration markedly decreased GPx and GRx activities in the liver tissues. GRx activities in the liver tissues increased significantly with the treatment of $\mathrm{PCMeOH}(0.5$ and $1.0 \mathrm{~g} / \mathrm{kg})$ and Indo $(10 \mathrm{mg} / \mathrm{kg})(P$ $<$.01-.001; Figure 5(b)). GPx activities in the liver tissues increased significantly with the treatment of $\mathrm{PCMeOH}(0.5$ and $1.0 \mathrm{~g} / \mathrm{kg})$ and Indo $(10 \mathrm{mg} / \mathrm{kg})(P<.001$; Figure $5(\mathrm{c}))$.

3.3.3. COX-2 Level. The activity of COX-2 increased significantly at the edema paw of mice after Carr administration for the third hour. COX-2 activity was inhibited significantly by treatment with $\mathrm{PCMeOH}(0.5$ and $1.0 \mathrm{~g} / \mathrm{kg})$ or Indo $(10 \mathrm{mg} / \mathrm{kg})(P<.05-.001 ;$ Figure 6$)$.

3.3.4. TNF- $\alpha$ Level. The level of TNF- $\alpha$ increased significantly at the edema paw of mice after Carr administration for $3 \mathrm{~h}$. At the third hour, TNF- $\alpha$ level was inhibited significantly after treatment with $\mathrm{PCMeOH}(0.5$ and $1.0 \mathrm{~g} / \mathrm{kg})$ or Indo $(10 \mathrm{mg} / \mathrm{kg})(P<.01-.001 ;$ Figure 7$)$.

\section{Discussion}

We have evaluated the putative analgesic and antiinflammatory activities of $\mathrm{PCMeOH}$ to demonstrate its painand inflammation-relieving effects. Two different analgesic testing methods were used with the objective of identifying possible peripheral and central effects of the test substances. In the acetic acid-induced writhing response, the visceral pain model, the analgesic mechanism of abdominal writhing was induced by acetic acid, which involves the release of arachidonic acid (AA) via COX and PG biosynthesis [34]. $\mathrm{PCMeOH}$ at the oral dose of $1.0 \mathrm{~g} / \mathrm{kg}$ significantly decreased the writhing response of acetic acid-induced mice. In addition, the formalin test involved a biphasic response: the direct effect of formalin on nociceptors in the early phase and inflammation in the late phase $[35,36]$. PCMeOH was administered orally $(0.5$ and $1.0 \mathrm{~g} / \mathrm{kg})$ to the mice, which 
produced dose-related inhibition late-phase pain but did not inhibit neurogenic (early phase) pain caused by intraplantar injection of formalin. These results suggested that $\mathrm{PCMeOH}$ possessed significant analgesic effect. The analgesic effect may be due to anti-inflammatory effect.

The Carr-induced inflammation was a standard model of screening for anti-inflammatory activity in various experimental compounds [37]. Carr-induced edema is characterized by the presence of PGs and other compounds of slow reaction [38]. COX-2 is an inducible isoform found in activated inflammatory cells that generates prostanoid mediators of inflammation [39]. Inhibition of COX-2 protein expression has also become the most popular target for screening anti-inflammatory agents and the study of pathogenesis and pathology of the inflammatory and nociceptive processes in animal models [40]. TNF- $\alpha$ is a major mediator in inflammatory responses, inducing innate immune responses by activating $\mathrm{T}$ cells and macrophages and stimulating the secretion of other inflammatory cytokines [41]. As cytokines are critical to the pathogenesis of inflammatory disorders, inhibition of their production and action can provide therapeutic benefits. Previous studies have shown significant correlations among cytokine production, COX2 protein expression and PG synthesis in the paw tissues of mice in which edema was invoked by intraplantar injection of Carr [42]. PCMeOH at dosages of $0.5-1.0 \mathrm{~g} / \mathrm{kg}$ significantly suppressed the protein expression of COX-2 level in the edema paw tissues of mice. The production of multiple proinflammatory cytokines, such as TNF- $\alpha$, in edema paw tissues of mice was also decreased by $\mathrm{PCMeOH}$ treatment. These results suggest that $\mathrm{PCMeOH}$ played a role in the antiinflammatory activities in the model of Carr-induced paw edema of mice through the inhibition of TNF- $\alpha$ and COX2 level.

The Carr-induced inflammatory response has been linked to neutrophil infiltration and the production of neutrophil-derived free radicals, such as hydrogen peroxide, superoxide and hydroxyl radicals, as well as to the release of other neutrophil-derived mediators [19]. Some studies demonstrate that the inflammatory effect induced by Carr is associated with free radicals. Free radicals and PG are released when Carr is administered for $1-6 \mathrm{~h} \mathrm{[43].} \mathrm{Also,}$ the paw edema was raised to maximum at the third hour [44]. Research has demonstrated that MDA production is caused by free radicals attacking plasma membranes [4547]. Thus, Carr-induced inflammatory effect results in the accumulation of MDA [48]. Glutathione is a known oxyradical scavenger. The enhancement of glutathione levels reduces MDA production. Cuzzocrea suggests that endogenous glutathione plays an important role against Carr-induced local inflammation [49]. PCMeOH and Indo showed antiinflammatory activity in Carr-induced mice paw edema at the third and fourth hours. PCMeOH significantly increased the SOD, GRx and GPx activities (Figure 5) and significantly decreased the MDA level (Figure 4). We assume that the suppression of MDA production is probably due to the increase of SOD, GRx and GPx activities.

This study demonstrated that $\mathrm{PCMeOH}$ exhibited antiinflammatory activity against Carr-induced paw edema and analgesic activity against nociceptive responses triggered in mice by i.p. acetic acid injection or intraplantar formalin injections. There are two possible mecha-nisms associated with the anti-inflammatory effect of $\mathrm{PCMeOH}$. One is reducing the amount of AA transformed to PGs by suppressing TNF- $\alpha$ and COX-2 level. The other is cleaning away free radicals by increasing the activity of anti-oxidant enzymes, such as SOD, GRx and GPx (Figure 8). The exact mechanism by which $\mathrm{PCMeOH}$ exerts its analgesic effect was related to its anti-inflammatory effect, and this serves as a possible rationale for the use of $\mathrm{PCMeOH}$ in traditional medicine for anti-inflammation.

\section{Acknowledgments}

This study was supported by grants from the Committee on National Science Council, Executive Yuan, Taiwan, (NSC 962320-B-039-016) and China Medical University (CMU96168, CMU97-085 and CMU97-142). I would like to thank Mr Albert Pape and Ms Yu-Fung Yang, Master of Graduate Institute of Linguistics at National Chung Cheng University, Chia-Yi, Taiwan, for reviewing the English language in this manuscript.

\section{References}

[1] D. Tousoulis, G. Davies, C. Stefanadis, P. Toutouzas, and J. A. Ambrose, "Inflammatory and thrombotic mechanisms in coronary atherosclerosis," Heart, vol. 89, no. 9, pp. 993-997, 2003.

[2] H. Rus and F. I. Niculescu, "Inflammation, aspirin, and the risk of cardiovascular disease," The New England Journal of Medicine, vol. 337, no. 6, p. 422, 1997, author reply 423-424.

[3] S. H. Ferreira, "Peripheral analgesia: mechanism of the analgesic action of aspirin like drugs and opiate-antagonists," British Journal of Clinical Pharmacology, vol. 10, supplement 2, pp. 237S-45S, 1980.

[4] V. Hajhashemi, A. Ghannadi, and S. K. Pezeshkian, "Antinociceptive and anti-inflammatory effects of Satureja hortensis L. extracts and essential oil," Journal of Ethnopharmacology, vol. 82, no. 2-3, pp. 83-87, 2002.

[5] A. G. Habeeb, P. N. Praveen Rao, and E. E. Knaus, "Design and synthesis of 4,5-diphenyl-4-isoxazolines: novel inhibitors of cyclooxygenase-2 with analgesic and antiinflammatory activity," Journal of Medicinal Chemistry, vol. 44, no. 18, pp. 2921-2927, 2001.

[6] J. H. Botting, "Nonsteroidal antiinflammatory agents," Drugs of Today, vol. 35, no. 4-5, pp. 225-235, 1999.

[7] Z. Zhao, J. Lu, K. Leung, C. L. Chan, and Z.-H. Jiang, "Determination of patchoulic alcohol in herba pogostemonis by GC-MS-MS," Chemical and Pharmaceutical Bulletin, vol. 53, no. 7, pp. 856-860, 2005.

[8] H.-C. Hsu, W.-C. Yang, W.-J. Tsai, C.-C. Chen, H.-Y. Huang, and Y.-C. Tsai, " $\alpha$-bulnesene, a novel PAF receptor antagonist isolated from Pogostemon cablin," Biochemical and Biophysical Research Communications, vol. 345, no. 3, pp. 1033-1038, 2006.

[9] M. Miyazawa, Y. Okuno, S.-I. Nakamura, and H. Kosaka, "Antimutagenic activity of flavonoids from Pogostemon cablin," Journal of Agricultural and Food Chemistry, vol. 48, no. 3, pp. 642-647, 2000. 
[10] "Pharmacopoeia. NCoPC," Pharmacopoeia of the People's Republic of China, 2000.

[11] Y. Yang, K. Kinoshita, K. Koyama et al., "Anti-emetic principles of Pogostemon cablin (Blanco) Benth," Phytomedicine, vol. 6, no. 2, pp. 89-93, 1999.

[12] F. Kiuchi, K. Matsuo, M. Ito, T. K. Qui, and G. Honda, "New sesquiterpene hydroperoxides with trypanocidal activity from Pogostemon cablin," Chemical and Pharmaceutical Bulletin, vol. 52, no. 12, pp. 1495-1496, 2004.

[13] K. Ichikawa, T. Kinoshita, and U. Sankawa, "The screening of Chinese crude drugs for $\mathrm{Ca}^{2+}$ antagonist activity: identification of active principles from the aerial part of Pogostemon cablin and the fruits of Prunus mume," Chemical and Pharmaceutical Bulletin, vol. 37, no. 2, pp. 345-348, 1989.

[14] E. J. Park, H. R. Park, J. S. Lee, and J. Kim, "Licochalcone A: an inducer of cell differentiation and cytotoxic agent from Pogostemon cablin," Planta Medica, vol. 64, no. 5, pp. 464-466, 1998.

[15] N. Paulino, A. P. Dantas, V. Bankova et al., "Bulgarian propolis induces analgesic and anti-inflammatory effects in mice and inhibits in vitro contraction of airway smooth muscle," Journal of Pharmacological Sciences, vol. 93, no. 3, pp. 307-313, 2003.

[16] D. Dubuisson and S. G. Dennis, "The formalin test: a quantitative study of the analgesic effects of morphine, meperidine, and brain stem stimulation in rats and cats," Pain, vol. 4, no. 2, pp. 161-174, 1977.

[17] S. Hunskaar and K. Hole, "The formalin test in mice: dissociation between inflammatory and non-inflammatory pain," Pain, vol. 30, no. 1, pp. 103-114, 1987.

[18] D. Salvemini, Z.-Q. Wang, P. S. Wyatt et al., "Nitric oxide: a key mediator in the early and late phase of carrageenan-induced rat paw inflammation," British Journal of Pharmacology, vol. 118, no. 4, pp. 829-838, 1996.

[19] J. Dawson, A. D. Sedgwick, J. C. W. Edwards, and P. Lees, "A comparative study of the cellular, exudative and histological responses to carrageenan, dextran and zymosan in the mouse," International Journal of Tissue Reactions, vol. 13, no. 4, pp. $171-185,1991$.

[20] E. O. Oruç and N. Üner, "Combined effects of 2,4-D and azinphosmethyl on antioxidant enzymes and lipid peroxidation in liver of Oreochromis niloticus," Comparative Biochemistry and Physiology Part C, vol. 127, no. 3, pp. 291-296, 2000.

[21] C. Rey, E. Vericel, G. Nemoz, W. Chen, P. Chapuy, and M. Lagarde, "Purification and characterization of glutathione peroxidase from human blood platelets. Age-related changes in the enzyme," Biochimica et Biophysica Acta, vol. 1226, no. 2, pp. 219-224, 1994.

[22] J. G. Müller, U. S. Bücheler, K. Kayser, R. H. Schirmer, D. Werner, and R. L. Krauth-Siegel, "Glutathione reductase in human and murine lung tumors: high levels of mRNA and enzymatic activity," Cellular and Molecular Biology, vol. 39, no. 4, pp. 389-396, 1993.

[23] T.-C. Lu, Y.-Z. Ko, H.-W. Huang, Y.-C. Hung, Y.-C. Lin, and W.-H. Peng, "Analgesic and anti-inflammatory activities of aqueous extract from Glycine tomentella root in mice," Journal of Ethnopharmacology, vol. 113, no. 1, pp. 142-148, 2007.

[24] S. Hunskaar, O. B. Fasmer, and K. Hole, "Formalin test in mice, a useful technique for evaluating mild analgesics," Journal of Neuroscience Methods, vol. 14, no. 1, pp. 69-76, 1985.

[25] I. Posadas, M. Bucci, F. Roviezzo et al., "Carrageenan-induced mouse paw oedema is biphasic, age-weight dependent and displays differential nitric oxide cyclooxygenase-2 expression," British Journal of Pharmacology, vol. 142, no. 2, pp. 331-338, 2004.
[26] N. Mascolo, R. Jain, S. C. Jain, and F. Capasso, "Ethnopharmacologic investigation of ginger (Zingiber officinale)," Journal of Ethnopharmacology, vol. 27, no. 1-2, pp. 129-140, 1989.

[27] L. A. Nakhai, A. Mohammadirad, N. Yasa et al., "Benefits of Zataria multiflora Boiss in experimental model of mouse inflammatory bowel disease," Evidence-Based Complementary and Alternative Medicine, vol. 4, no. 1, pp. 43-50, 2007.

[28] O. H. Lowry, N. J. Rosebrough, A. L. Farr, and R. J. Randall, "Protein measurement with the Folin phenol reagent," The Journal of Biological Chemistry, vol. 193, pp. 265-275, 1951.

[29] H. P. Misra and I. Fridovich, "The role of superoxide anion in the autoxidation of epinephrine and a simple assay for superoxide dismutase," Journal of Biological Chemistry, vol. 247, no. 10, pp. 3170-3175, 1972.

[30] L. Flohe and W. A. Gunzler, "Assays of glutathione peroxidase," Methods in Enzymology, vol. 105, pp. 114-121, 1984.

[31] I. Carlberg and B. Mannervik, "Glutathione reductase," Methods in Enzymology, vol. 113, pp. 484-490, 1985.

[32] C.-W. Cheng, C.-K. Chen, Y.-S. Chen, and L.-Y. Chen, "Determination of Schistosoma japonicum circulating antigens in dilution serum by piezoelectric immunosensor and $\mathrm{S} / \mathrm{N}$ enhancement," Biosensors and Bioelectronics, vol. 24, no. 1, pp. 136-140, 2008.

[33] S.-C. Chun, S. Y. Jee, S. G. Lee, S. J. Park, J. R. Lee, and S. C. Kim, "Anti-inflammatory activity of the methanol extract of Moutan Cortex in LPS-activated Raw264.7 cells," EvidenceBased Complementary and Alternative Medicine, vol. 4, no. 3, pp. 327-333, 2007.

[34] H.-J. Koo, K.-H. Lim, H.-J. Jung, and E.-H. Park, "Antiinflammatory evaluation of gardenia extract, geniposide and genipin," Journal of Ethnopharmacology, vol. 103, no. 3, pp. 496-500, 2006.

[35] C. Tohda, N. Nakayama, F. Hatanaka, and K. Komatsu, "Comparison of anti-inflammatory activities of six Curcuma rhizomes: a possible curcuminoid-independent pathway mediated by Curcuma phaeocaulis extract," Evidence-Based Complementary and Alternative Medicine, vol. 3, no. 2, pp. 255-260, 2006.

[36] H. Y. Chang, M. J. Sheu, C. H. Yang et al., "Analgesic effects and the mechanisms of anti-inflammation of hispolon in mice," Evidence-Based Complementary and Alternative Medicine, 2009.

[37] M. Di Rosa, J. P. Giroud, and D. A. Willoughby, "Studies on the mediators of the acute inflammatory response induced in rats in different sites by carrageenan and turpentine," Journal of Pathology, vol. 104, no. 1, pp. 15-29, 1971.

[38] W. G. Spector and D. A. Willoughby, "The inflammatory response," Bacteriological Reviews, vol. 27, pp. 117-154, 1963.

[39] D. A. Sawatzky, I. L. Megson, and A. G. Rossi, "Sildenafil offers protection against NSAID-induced gastric injury," British Journal of Pharmacology, vol. 146, no. 4, pp. 477-478, 2005.

[40] F. Nantel, D. Denis, R. Gordon et al., "Distribution and regulation of cyclooxygenase-2 in carrageenan-induced inflammation," British Journal of Pharmacology, vol. 128, no. 4, pp. 853-859, 1999.

[41] B. Beutler and A. Cerami, "The biology of cachectin/TNFa primary mediator of the host response," Annual Review of Immunology, vol. 7, pp. 625-655, 1989.

[42] W.-H. Park, S.-Y. Park, H.-M. Kim, and C.-H. Kim, "Effect of a Korean traditional formulation, Hwaotang, on superoxide generation in human neutrophils, platelet aggregation in human blood, and nitric oxide, prostaglandin E2 production and paw oedema induced by carrageenan in mice," 
Immunopharmacology and Immunotoxicology, vol. 26, no. 1, pp. 53-73, 2004.

[43] S. P. Dudhgaonkar, S. K. Tandan, A. S. Bhat, S. H. Jadhav, and D. Kumar, "Synergistic anti-inflammatory interaction between meloxicam and aminoguanidine hydrochloride in carrageenan-induced acute inflammation in rats," Life Sciences, vol. 78, no. 10, pp. 1044-1048, 2006.

[44] M. Kirkova, T. Kassabova, and E. Russanov, "In vivo effects of indomethacin-I: activity of antioxidant enzymes and lipid peroxidation," General Pharmacology, vol. 23, no. 3, pp. 503507, 1992.

[45] D. R. Janero, "Malondialdehyde and thiobarbituric acidreactivity as diagnostic indices of lipid peroxidation and peroxidative tissue injury," Free Radical Biology and Medicine, vol. 9, no. 6, pp. 515-540, 1990.

[46] P. Chaturvedi, "Inhibitory response of Raphanus sativus on lipid peroxidation in albino rats," Evidence-Based Complementary and Alternative Medicine, vol. 5, no. 1, pp. 55-59, 2008.

[47] S. Shetty, S. Udupa, and L. Udupa, "Evaluation of antioxidant and wound healing effects of alcoholic and aqueous extract of Ocimum sanctum Linn in rats," Evidence-Based Complementary and Alternative Medicine, vol. 5, no. 1, pp. 95-101, 2008.

[48] D. Bilici, E. Akpinar, and A. Kiziltunç, "Protective effect of melatonin in carrageenan-induced acute local inflammation," Pharmacological Research, vol. 46, no. 2, pp. 133-139, 2002.

[49] S. Cuzzocrea, G. Costantino, B. Zingarelli, E. Mazzon, A. Micali, and A. P. Caputi, "The protective role of endogenous glutathione in carrageenan-induced pleurisy in the rat," European Journal of Pharmacology, vol. 372, no. 2, pp. 187197, 1999. 


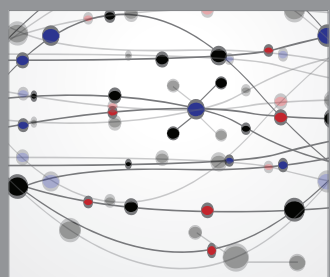

The Scientific World Journal
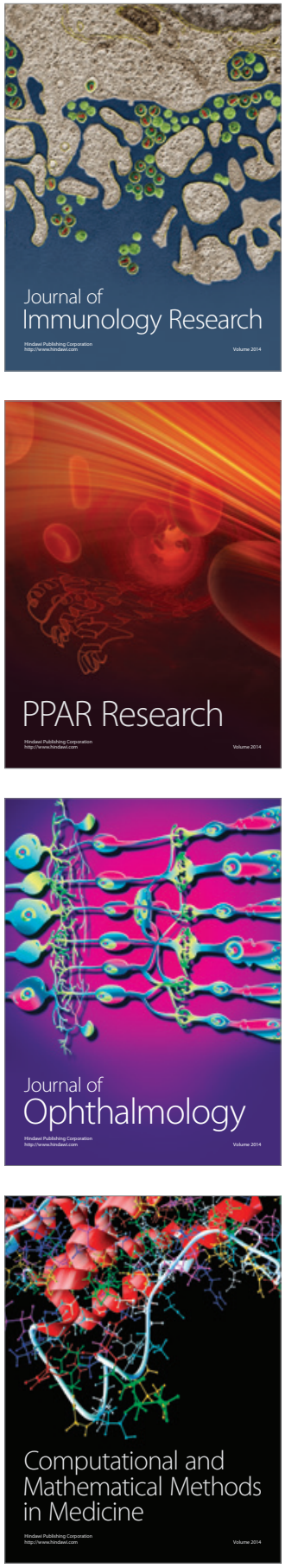

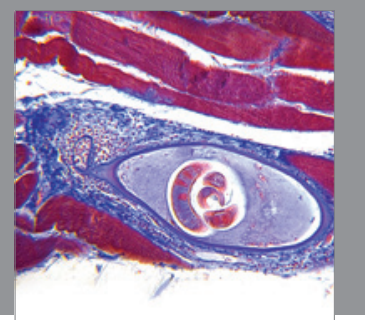

Gastroenterology

Research and Practice
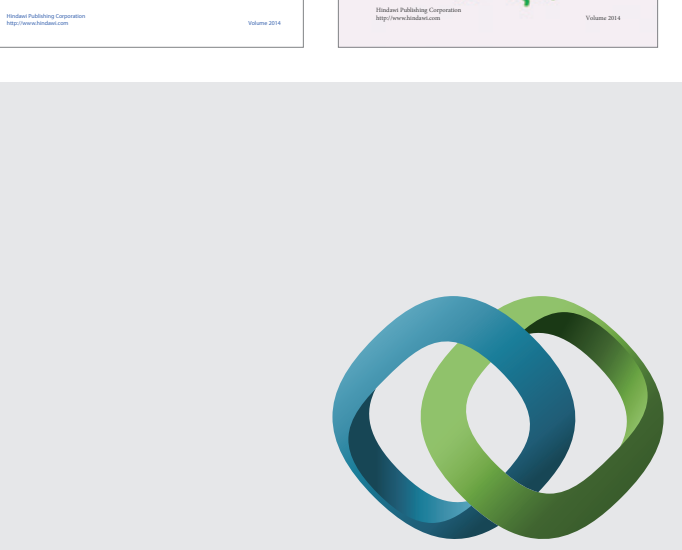

\section{Hindawi}

Submit your manuscripts at

http://www.hindawi.com
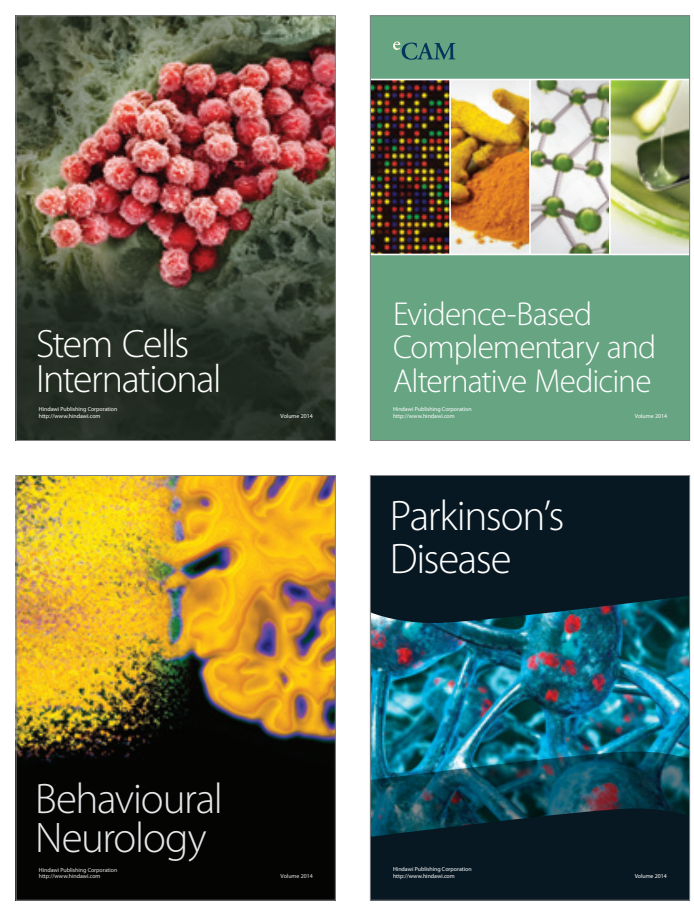

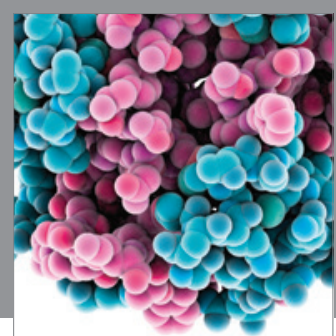

Journal of
Diabetes Research

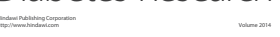

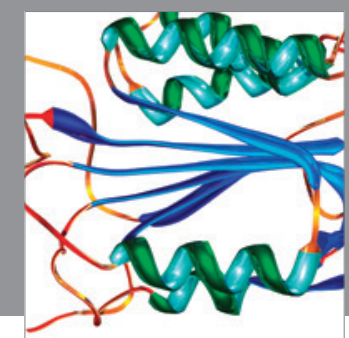

Disease Markers
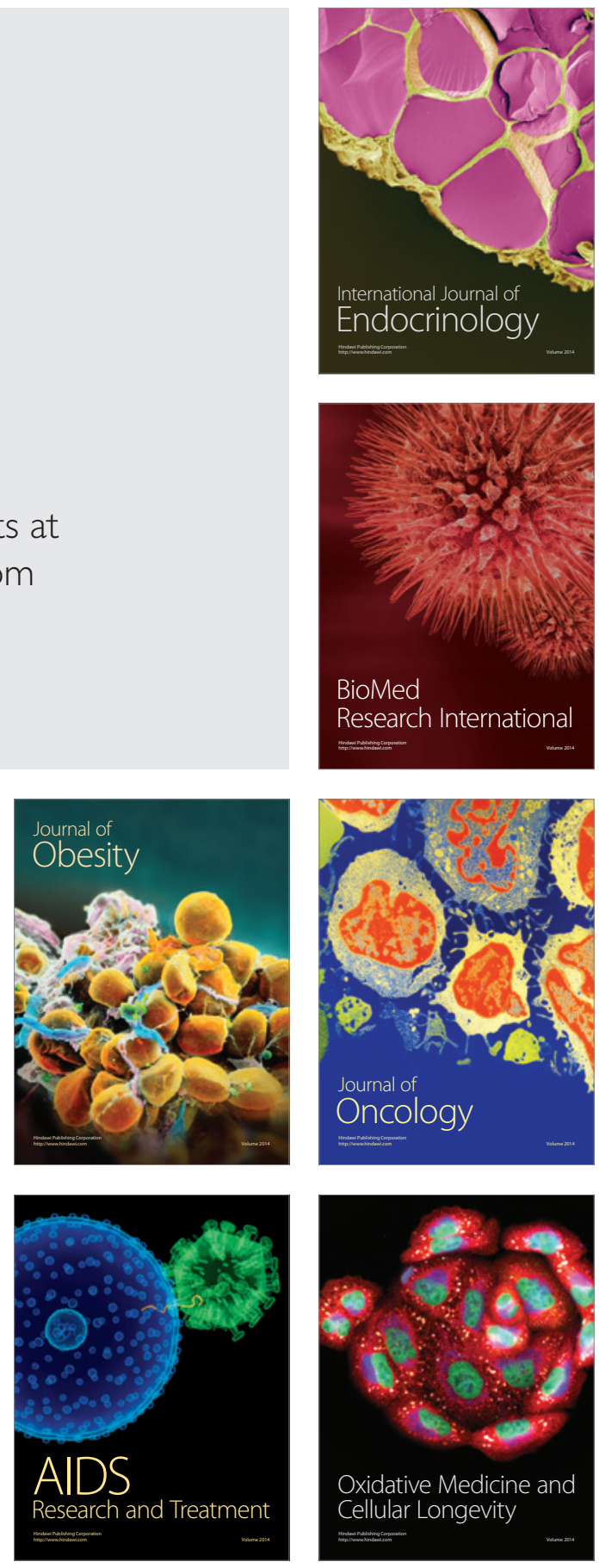